\title{
Exploration of Grit and Emotional Intelligence and Success in a Doctor of Physical Therapy Program
}

\author{
Karen Huhn \\ Husson University, huhnk@husson.edu \\ Brittney Rusinski DPT \\ Husson University, rusinskib@husson.edu \\ Amanda Saucier DPT \\ Husson University, sauciera@husson.edu \\ Victoria McIntyre DPT \\ Husson University, mcintyrev@husson.edu \\ Teresa Rock DPT \\ Husson University, rockt@husson.edu \\ See next page for additional authors
}

Follow this and additional works at: https://nsuworks.nova.edu/ijahsp

Part of the Occupational Therapy Commons, and the Physical Therapy Commons

\section{Recommended Citation \\ Huhn K, Rusinski B, Saucier A, Mclntyre V, Rock T, Nelson M, et al. Exploration of Grit and Emotional Intelligence and Success in a Doctor of Physical Therapy Program. The Internet Journal of Allied Health Sciences and Practice. 2021 Jan 01;19(1), Article 10.}

This Manuscript is brought to you for free and open access by the College of Health Care Sciences at NSUWorks. It has been accepted for inclusion in Internet Journal of Allied Health Sciences and Practice by an authorized editor of NSUWorks. For more information, please contact nsuworks@nova.edu. 


\title{
Exploration of Grit and Emotional Intelligence and Success in a Doctor of Physical Therapy Program
}

\begin{abstract}
Background: Higher education programs that admit students to sequential curricula incur a substantial financial loss when an enrolled student fails to continue in the program for whatever reason. In many instances, the seat cannot be filled, and valuable tuition dollars often over $\$ 90,000$ per student is lost to the institution. In addition to financial loss, Doctor of Physical Therapy (DPT) programs are required to report and explain rates to the Commission for Accreditation of Physical Therapy Education (CAPTE). Admission committees at Doctor of Physical Therapy programs seek candidates that will be successful in the program and pass the National Physical Therapy Examination (NPTE). Purpose: The purpose of this study was to explore relationships of non-cognitive characteristics (grit and emotional intelligence) and Grade Point Average (GPA) in the first year of a DPT program with the intent to potentially identify students who might benefit from remediation/intervention to prevent attrition. Methods: Forty-two students in the first year of a Doctor of Physical Therapy program completed the Grit scale and the Mayers-Salovey Emotional Intelligence test early in the fall semester of year one. Results: There were no significant relationships between grit or emotional intelligence and academic success in the first year of a DPT program. Conclusions: The current study provides preliminary information related to non-cognitive factors of grit and emotional intelligence and success in a Doctor of Physical Therapy program.
\end{abstract}

\section{Author Bio(s)}

Karen Huhn PT PhD is Professor and Chair School of Physical Therapy Husson University, Bangor Maine.

At the time of this study, the other authors were students at Husson University. They are no longer students there.

\section{Authors}

Karen Huhn, Brittney Rusinski DPT, Amanda Saucier DPT, Victoria Mclntyre DPT, Teresa Rock DPT, Makeala Nelson DPT, Yieng Huah Tham DPT, and Courtney Duval DPT 


\title{
IITAHSP \\ The Internet Joumnal of Allied Health Sciences and Practice \\ Dedicated to allied health professional practice and education
}

Vol. 19 No. 1 ISSN 1540-580X

\section{Exploration of Grit and Emotional Intelligence and Success in a Doctor of Physical Therapy Program}

\author{
Karen Huhn \\ Brittney Rusinski \\ Amanda Saucier \\ Victoria McIntyre \\ Teresa Rock \\ Makeala Nelson \\ Yieng Huah Tham \\ Courtney Duval \\ Husson University \\ United States
}

\begin{abstract}
Background: Higher education programs that admit students to sequential curricula incur a substantial financial loss when an enrolled student fails to continue in the program for whatever reason. In many instances, the seat cannot be filled, and valuable tuition dollars often over $\$ 90,000$ per student is lost to the institution. In addition to financial loss, Doctor of Physical Therapy (DPT) programs are required to report and explain rates to the Commission for Accreditation of Physical Therapy Education (CAPTE). Admission committees at Doctor of Physical Therapy programs seek candidates that will be successful in the program and pass the National Physical Therapy Examination (NPTE). Purpose: The purpose of this study was to explore relationships of noncognitive characteristics (grit and emotional intelligence) and Grade Point Average (GPA) in the first year of a DPT program with the intent to potentially identify students who might benefit from remediation/intervention to prevent attrition. Methods: Forty-two students in the first year of a Doctor of Physical Therapy program completed the Grit scale and the Mayers-Salovey Emotional Intelligence test early in the fall semester of year one. Results: There were no significant relationships between grit or emotional intelligence and academic success in the first year of a DPT program. Conclusions: The current study provides preliminary information related to non-cognitive factors of grit and emotional intelligence and success in a Doctor of Physical Therapy program.
\end{abstract}

Keywords: admissions, non-cognitive factors 


\section{INTRODUCTION}

Higher education programs have a substantial interest in retaining students they admit. Retention is especially true for graduatelevel programs such as the Doctor of Physical Therapy (DPT), which can often incur a higher cost ratio for a university due to costs of required equipment, space, faculty, and accreditation standards. When a student fails to progress in such a program, the institution may suffer substantial financial loss. In many instances, the seat cannot be filled, and valuable tuition dollars often over $\$ 90,000$ per student is lost to the institution. ${ }^{1}$ Besides the financial loss, DPT programs are required to report attrition and explain attrition and National Physical Therapy Exam (NTPE) pass rates to the Commission for Accreditation of Physical Therapy Education (CAPTE). ${ }^{2}$ Attrition and pass rate data can affect a program's accreditation status, which can again impact a college or university financial status. The NPTE pass rate also serves as a marketing statistic to attract students to a program.

In addition to financial implications for colleges and universities, there are student factors to be considered related to attrition. Students who do not continue in a DPT program most likely incur substantial debt for credits that do not lead to a degree. They may suffer adverse emotional effects related to not being successful at something they most likely worked very hard to achieve. Admission to a DPT program remains highly competitive, and some often-qualified candidates do not get admitted because of enrollment caps. Enrolling a student at risk for attrition may prevent another qualified student from entering in the program.

Identifying traits and characteristics of unsuccessful students and those that thrive in a DPT program may help to ameliorate both programmatic and student factors related to attrition. Additionally, identifying traits and characteristics that put a student at risk may help program to potentially identify students who might benefit from remediation early in the academic program, thereby preventing attrition and financial loss for the institution.

Previous work has reported on both cognitive and non-cognitive factors related to academic success measured by GPA and NPTE pass rates. In the cognitive domain, undergraduate grade point average (UGPA) has consistently correlated with GPA in the physical therapy program. ${ }^{3-5}$ However, a recent study reported UGPA only associated with GPA in the first professional year but failed to have predictive value in successive years. ${ }^{6}$ Meiners and Rush reported first-year GPA was a significant predictor of NPTE score, explaining $23 \%$ of the variance. ${ }^{7}$ GRE scores have also been reported as predictive, especially when included in regression with other academic scores. ${ }^{8-11}$

Non-cognitive factors such as the Big Five Personality Scale, and the Personality Survey for Coping Inventory for Stressful Situations failed to predict NPTE success. ${ }^{10}$ Lewis explored the Mayers-Salovey-Caruso Emotional Intelligence Test (MSCEIT) and NPTE scores with DPT students and found no correlation between the two. ${ }^{12}$ Although the associations were not significant, some differences did exist between emotional intelligence scores assessed during the first year of the program and those who passed the NPTE and those that did not $(p=0.05)$. The authors suggest caution when interpreting this finding as only 14 of 151 participants failed the NPTE. ${ }^{12}$ Hollman reported a small but significant relationship between scores on behavioral interviews and first-time pass of the NPTE. ${ }^{11}$

While this previous work is informative, it has primarily focused on GPA and NPTE with little emphasis on early identification of students at risk of attrition. Other than undergraduate GPA, little is known about traits and characteristics that may lead to attrition. Therefore, there is a need to continue to explore the characteristics and traits of DPT students.

Merriam-Webster describes grit as "firmness of mind or spirit: unyielding courage in the face of hardship or danger."13 Duckworth describes it as passion and perseverance for long term goals. ${ }^{14}$ Duckworth reported grittier individuals tended to obtain higher academic degrees than those who were less gritty. ${ }^{15}$ Exploration of grit in first year physical therapy students and its potential relationship to NPTE scores has yet to be explored. However, grit has been found to predict success and retention in other disciplines. Grit is a significant predictor of academic achievement in pharmacy students who reported a GPA of $\geq 3.5$ but not for students whose GPA was < 3.0.16 In contrast, Jason et. al reported no correlation between grit and academic achievement operationally defined as a GPA $>3.0$ for pharmacy students. ${ }^{17}$ Another study reported high grit scores were associated with retention in teachers ${ }^{18}$ However, this study used a self-created rubric for scoring grit, so a direct comparison to other studies is not possible. Miller et. al reported medical students who completed the program in four years versus five years had higher grit scores. He also reported a correlation between grit scores and success on the United States Medical Licensing Exam (USMLE) $2 \mathrm{CS} .{ }^{19}$ The relationship between high grit scores and retention also extends beyond academia. For example, grit has been reported to predict retention in first year United States Military Academy cadets. Cadets that were retained after their first year were twice as likely to have a higher grit score than those who left the academy. ${ }^{20}$

According to Salovey and Mayer (1990), emotional intelligence (EI) is defined as "the subset of social intelligence that involves the ability to monitor one's own and others' feelings and emotions, to discriminate among them and to use this information to guide 
one's thinking and actions." ${ }^{21} \mathrm{~A}$ review of the literature suggests a relationship exists between El and academic success. Partido reported a moderate correlation between dental students' El scores and GPA $(r(45)=0.404, p<0.05)$. ${ }^{22}$ Rode found El played a role in both the Kaplan Nursing Assessment Test and the National Council Licensure Examination (NCLEX) with El scores accurately classifying $84.9 \%$ of those who passed or failed the NCLEX. ${ }^{23}$ Another study reported El scores were a significant predictor of GPA for both first and final year medical students. ${ }^{24}$ High scores of El were also a significant predictor of perceived stress in first year medical students. ${ }^{25}$ Additionally, El dimensions predicted satisfaction with life over a period of one year for medical, physiotherapy, and nursing students indicating El positively predicts students' well-being. ${ }^{26}$

The purpose of this study was to explore relationships of non-cognitive characteristics, specifically, grit and emotional intelligence with GPA in the first year of a DPT program with the intent to potentially identify students who might benefit from remediation/intervention to prevent attrition.

\section{METHODS \\ Participants}

Participants were forty-two students beginning the professional phase of a six-year early assurance Doctor of Physical Therapy program at a private, rural university. Twenty-eight participants were early assurance (freshman admit) and fourteen were graduate students (completed BS degree prior to beginning the DPT program). Nineteen identified as male and twenty-three as female with an age range of 19-42. All 42 students were invited to participate in the research with the only inclusion criteria being a student in the first year of the professional phase of the graduate DPT program. The Human Research Review Committee approved the expedited study.

Table 1. Subject Demographics

\begin{tabular}{lc}
\hline Characteristic & Subjects $(n=42)$ \\
\hline Gender (M/F) & $19 / 23$ \\
Admission Type (Early & $28 / 14$ \\
assurance/Graduate & \\
Age, Mean (range) & $24(19-42)$ \\
\hline
\end{tabular}

\section{Design}

The research study was an exploratory quantitative design. Quantitative measures included the 18 item Grit Scale and the MayersSalovey-Caruso Emotional Intelligence Test (MSCEIT), and grade point average at two time points. Participants provided informed consent and completed the 18-item Grit Scale in a paper-based format during the fall semester of first professional year. Participants were then sent an email link to access the web-based MSCEIT. Three subsequent email reminders were sent approximately one week apart to remind participants to complete the MSCEIT. GPA was obtained from students' academic records.

\section{Outcome Measures :}

Duckworth and colleagues' (2007) 12-item Grit Scale is a self-report measure in which participants score questions about behavior on a scale from "Not like me at all" to "Very much like me." Duckworth indicates the scale was designed to assess individual differences rather than within-individual differences and it is unclear if the scale can be used as a valid tool to assess changes due to interventions. ${ }^{27}$ The maximum score that can be achieved on the scale is 5 for "extremely gritty" and the lowest score possible is 1 for "not gritty at all." The scale takes 5-15 minutes to complete. Predictive validity, internal consistency and test-retest stability have been established. 28

The MSCEIT is a proprietary ability-based test designed to measure four aspects of the emotional intelligence model by Mayer and Salovey. The four aspects include perceiving emotions, facilitating thought, understanding emotions, and managing emotions. The test consists of 141 items and takes 30-45 minutes to complete. ${ }^{29} \mathrm{~A}$ variety of scores are generated including the total emotional intelligence score, two area scores, four branch scores, eight task scores, and three supplemental scores ${ }^{29}$ The validity, internal consistency, and test re-test reliability of the MSCEIT have been well-established. ${ }^{30}$

Data were entered into an excel spreadsheet that included each participants' grit scores, the total emotional intelligence score of the MSCEIT, GPA at the end of the fall semester of year one, and GPA at the end of the fall semester of year two. An additional column with a dichotomous variable was added to the spreadsheet to indicate retention (1) vs dismissed (2). A final column also with a dichotomous variable indicated whether the student was early assurance (1) or a graduate student (2). This spreadsheet was then imported into IBM SPSS statistics, version 24 for all data analysis. ${ }^{31}$ Prior to statistical analysis, normal distribution was confirmed via visual inspection and Shapiro-Wilk statistic. Pearson product correlations were used to explore relationships between Grit Scale score and GPA and MSCEIT and GPA. To explore differences between groups of retained and dismissed students and 
graduate and early assurance groups, an ANOVA was conducted. Alpha was established at 0.05 for all statistical analysis. Power was not calculated a priori as this was a cohort study and it was not possible to recruit additional subjects.

\section{RESULTS}

Forty of forty-two subjects completed the Grit Scale for a 95\% response rate, and twenty-eight of forty-two completed the MSCEIT for $66 \%$ response rate. Figure 1 demonstrates the distribution of scores for Grit Scale scores $(M=3.8, S D=.4)$. Figure 2 demonstrates the distribution of scores for the MSCEIT (M $=97.88, S D=10.51)$. Twenty-four or $41 \%$ of subjects had grit scores of 4.0 or higher, and only two subjects had a grit score of 3 or lower. Table 2 provides means of subjects' Grit Scale, MSCEIT and GPA. Table 3 provides results of the correlation. The Pearson Correlation indicated no association between grit and GPA1 ( $r$ (41) $=.031, p=0.85)$ or between MSCEIT and GPA1 $(r(39)=0.18, p=.39)$. There was also no association between grit and GPA 2 $(r(36)=0.09, p=0.62)$ or MSCEIT and GPA 2 ( $r(31)=0.09, p=0.62)$.

Results of the ANOVA indicate there were no significant differences in grit $(f(1,39)=0.650, p=0.42)$ or MSCEIT $(f(1,27)=2.9$, $p=0.10)$ between the early assurance students and the graduate students. There was no effect for $\operatorname{sex}(f(1,38)=.019, p=.89)$ for the Grit Scale or the MSCEIT $(f(1,26)=3.6, p=.06)$.

There were also no significant differences in Grit Scale score $(f(1,38)=0.00, p=0.98)$ or MSCEIT $(f(1,26)=0.14, p=0.91)$ between dismissed students and retained students. Four students were dismissed for academic reasons and one for two safety fails on a practical exam. All four students dismissed for academic reasons received four course grades of $\mathrm{C}$ or lower. Table 4 provides the Grit Scale score and MSCEIT for subjects dismissed from the program. Two additional students left the cohort for personal reasons when they decided physical therapy was not the career for them. Both were early assurance students.

Table 2. Mean Scores

\begin{tabular}{lll}
\hline Data & Mean (SD) & Median \\
\hline Grit Scale Score & $3.94(.40)$ & 4.0 \\
MSCEIT & $98.17(10.24)$ & 98.69 \\
GPA & $3.16(.41)$ & 3.2 \\
\hline
\end{tabular}

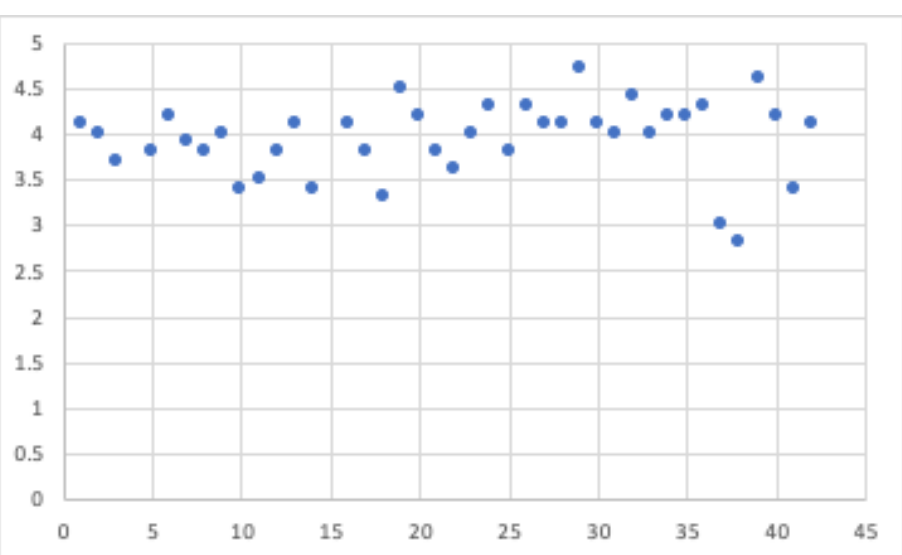

Figure 1. Distribution of Grit Scores 


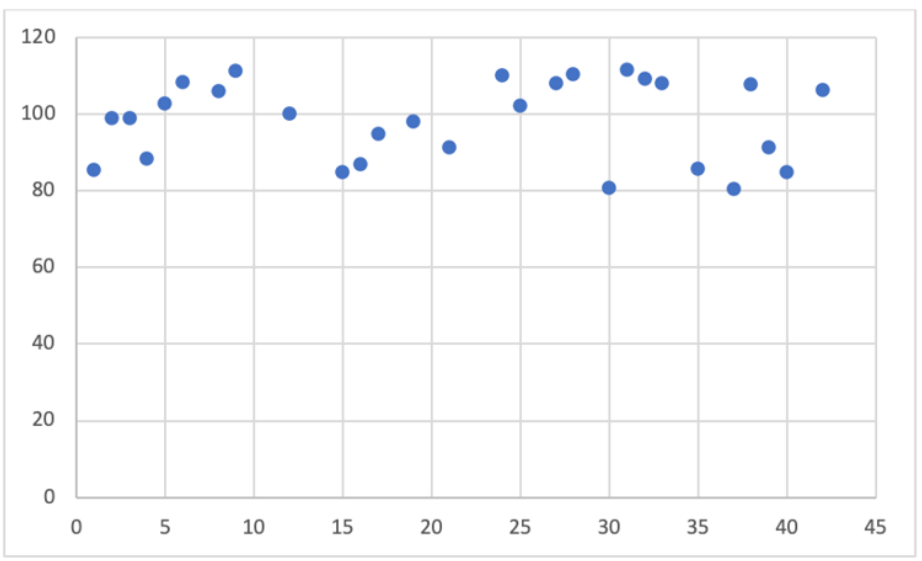

Figure 2. Distribution of Mayer-Salovey-Caruso Emotional Intelligence Scale

Table 3. Correlations

\begin{tabular}{lrrrr}
\hline & \multicolumn{1}{c}{ Initial Grit Scale Score } & El Score & \multicolumn{2}{c}{ GPA 1 } \\
\hline Initial Grit Scale Score & 1 & .046 & -.031 \\
EI Score & .046 & 1 & .187 \\
GPA 1 & -.031 & .187 & 1 \\
\hline
\end{tabular}

Table 4. Academic Dismissals

\begin{tabular}{lcc}
\hline Student ID code & $\begin{array}{l}\text { Grit Score } \\
(\mathrm{M}=3.94)\end{array}$ & $\begin{array}{l}\text { MSCEIT Score } \\
(\mathrm{M}=98.17)\end{array}$ \\
\hline 35 & 3.7 & 98.6 \\
68 & 4.2 & 108 \\
71 & 4.1 & 86.83 \\
77 & 3.4 & Not completed \\
$6^{*}$ & 3.3 & Not completed \\
\hline
\end{tabular}

*safety fails

\section{DISCUSSION}

The purpose of this study was to explore relationships of non-cognitive characteristics (grit and emotional intelligence) and GPA in the first year of a DPT program with the intent to potentially identify students who might benefit from remediation/intervention to prevent attrition. The results indicate neither a students' grit nor emotional intelligence is predictive of first year GPA or retention and therefore may not be useful in identifying students who might benefit from early remediation/intervention.

Grit has been associated with a range of positive academic outcomes such as academic performance and retention across academic grades however, mixed results have been reported in the literature thus far related to grit and GPA in higher education. ${ }^{32}$ Duckworth reported grit was not the best predictor of cumulative first year GPA at the United States Military Academy. ${ }^{15}$ Studies in Pharmacy reported conflicting findings relative to grit and GPA with one study reporting no correlation between grit and academic success defined as a GPA > 3.0.16 In contrast, Pate found those who obtained D or F grades had a lower grit score (3.6) than those who did not obtain a grade of $\mathrm{D}$ or $\mathrm{F}$ (3.7), but it did not reach statistical significance. ${ }^{22} \mathrm{~A}$ study designed to explore root causes of medical resident attrition reported residents who had below median grit score were more likely to leave a residency program than those with above median grit scores. ${ }^{33}$

The mean grit score of subjects in this study of 3.94 is slightly higher than those reported by Halbur et al of DPT students which was 3.85 and those reported by Palisoc and Pate of pharmacy students of 3.8 and 3.7.16,22,34 Miller-Mateo reported graduating medical students had a mean grit score of 4.01. ${ }^{19} \mathrm{~A}$ maximum score of 5 is considered "extremely gritty" and a score of 1 indicating "not gritty at all."14 Further categorization of grit scores have not been reported in the literature, so examining scores across types of subjects is the only way to compare and contrast different groups. Grit scores of subjects in this study could be considered 
relatively high indicating a certain degree of "grittiness" upon entry into the DPT program. It is not surprising to find DPT students are "gritty" due to the competitive nature of getting accepted into a program. There were no statistical differences between mean grit scores of the early assurance students (4.0) and the graduate students (3.9). This finding is consistent with others who did not find a correlation between grit and age.19,34

The mean emotional intelligence total score was 98.52 which is considered low average according the MSCEIT authors. ${ }^{35}$ This mean is slightly lower than those reported by Lewis (101.69) which is indicative of high average El skills. Lewis also studied DPT students; however, they were second and third year students whereas the participants in this study were first year primarily early assurance students. ${ }^{12}$ The finding of a lack of correlation between El scores and GPA adds to other contradictory findings in the literature. Several authors have reported correlations between MSCEIT and academic achievement.30,36-38 Codier noted a significant correlation between MSCEIT scores and GPA in the first year of a Bachelor of Science Nursing program. ${ }^{39}$ In contrast, Beauvais reported a non-significant correlation between MSCEIT and undergraduate nursing students' GPA and a moderate correlation for graduate students. ${ }^{8} \mathrm{~A}$ study of fifty-six DPT students found no correlation between total MSCEIT score with GRE, pre-requisite GPA scores, or scores on the Clinical Performance Instrument (CPI). ${ }^{12}$ One possible explanation for a lack of a relationship between El and GPA in this particular sample was homogeneity in GPA (mean $=3.16, \mathrm{SD}=0.41$ ). Emotional intelligence refers to "the ability to recognize the meanings of emotions and their relationships, and to reason and problem-solve on the basis of them." 40 p 267 We chose to explore El due to the high levels of anxiety and stress reported by DPT students, and we felt these high levels of stress and anxiety might affect their ability to learn which is traditionally measured by GPA. We studied students in year one of a program which typically focuses on foundational sciences which may have potentially lower expectations related to reasoning. It is also possible that the assessments used in the first year of a program do not require reasoning and problem-solving based on emotion as described in the description of El. Measures of El may correlate more with reasoning and problem-solving in a clinical setting rather than on written assessments where emotion is often not a factor.

A first-year GPA is the most consistently reported predictor of NPTE success so it is possible that grit and El do not play a significant role in predicting NPTE success. However, it is possible grit and/or El play a role in a students' ability to persevere through the entire DPT program and be successful on the NPTE. Duckworth further describes grit as "maintaining effort and interest over years despite failure, adversity, and plateaus in progress". ${ }^{15}$ So while grit and El may not be predictive of first year GPA, there may still be value in completing a longitudinal study to explore the relationship between these non-cognitive factors and NPTE success.

\section{CONCLUSION}

The current study provides preliminary information to enhance our understanding of the role of non-cognitive factors of grit and emotional intelligence and GPA in the first year of a Doctor of Physical Therapy program. It appears neither grit nor emotional intelligence play a substantial role in succeeding in the first year of a DPT program and therefore may not be helpful in determining which students might benefit from early intervention to prevent attrition. There are limitations to the current study with the main one being it was only done at one DPT program limiting the generalizability of the findings. Further research is necessary to continue to explore factors that might identify characteristics or traits of students who will be are at risk of attrition in DPT programs.

\section{References}

1. Commission on Accrediation in Physical Therapy Education. Aggregate Program Data. Alexandria, VA: Commision on Accreditation in Physical Therapy Education;2019.

2. Commission on Accrediation in Physical Therapy Education. Standards and Required Elements for Accreditation of Physical Therapist Education Programs. In. Alexandria, VA: Commission on Accreditation in Physical Therapy Education; 2020.

3. Maring J, Costell E, Ulfers M, Zuber E. Curriculum, faculty and cohort variables predicting physical therapist assistant program graduate success on the National Physical Therapy Examination. Journal of Physical Therapy Education. 2013;27(2):33-40.

4. $\quad$ Riddle D, Utzman R, Jewell D, Pearson S, Kong X. Academic difficulty and program level variables predict performance on the National Physical Therapy Examinaion for Licensure: A population based cohort study. Physical Therapy. 2009;89:1182-1191. doi:10.2522/ptj.20080400

5. Thieman T, Weddle M, Moore M. Predicting academic, clinical, and licensure examination performance in professional (entry-level) master's degree program in physical therapy. Journal of Physical Therapy Education. 2003;17(2). 
6. Coleman-Salgado B. The Relationship of Preadmission Academic Variables to Academic Performance in a Doctor of Physical Therapy Program. J Allied Health. 2019;48(1):e9-e14.

7. Meiners KM, Rush DK. Clinical Performance and Admission Variables as Predictors of Passage of the National Physical Therapy Examination. J Allied Health. 2017;46(3):164-170.

8. Beauvais A, Stewart J, DeNisco S, Beauvais J. Factors related to academic success among nursing students: A descriptive correlational research study. Nurse Education Today. 2014;34:918-923. doi:10.1016/j.nedt.2013.12.005

9. Dockter M. An analysis of physical therapy preadmission factors on academic success and sucess on the National Licensing Examination. Journal of Physical Therapy Education. 2001;15(1).

10. Galleher $C$, Rundquist $P$, Barker $D$, Chang W. Determining cognitive and non-cognitive predictors of success on the National Physical Therapy Examination. The Internet Journal of Allied Health Sciences and Practice. 2012;10(4).

11. Hollman J, Rindflesch A, Youdas J, Drause D, Hellyer N, Kinlaw D. Retrospective analysis of the behavoral interview and other preadmission variables to predict licensure examination outcomes in physical therapy. Journal of Allied Health. 2008;37. PMID: 18630785

12. Lewis E. Emotional intelligence as a predictor for clinnical performance in professional physical therapy students. The Internet Journal of Allied Health Sciences and Practice. 2010;8(4).

13. Merriam-Webster. Merriam-Webster Online Dictionary. Merriam Webster. https://www.merriam-webster.com/. Published 2020. Accessed 2/5/2020, 2020.

14. Duckworth A. GRIT The power of passion and perseverance. New York, NY: Scribner; 2016.

15. Duckworth AL, Peterson C, Matthews MD, Kelly DR. Grit: perseverance and passion for long-term goals. J Pers Soc Psychol. 2007;92(6):1087-1101. PMID: 17547490

16. Palisoc A, Matumoto R, Ho J, perry P, Tang t, E I. Relationship between grit with academic performance and attainment of postraduate training in pharmacy students. American Journal of Pharmaceutical Education. 2017;81(4)

17. Jason A, Matsumoto R, Ho J, Perry P, Tang T, Ip E. Relationship between grit with academic performance and attainment of postgraduate training in pharmacy students. American Journal of Pharmaceutical Education. 2017;81(4). PMID: 28630508

18. Robertson-Kraft C, Duckworth A. True Grit: Trait-level perseverance and passion for long-term goals predicts effectiveness and retention among novice teachers. Teachers College Record. 1970;116(3). PMID: 2536406

19. Miller-Matero L, Martinez S, MacLean K, Yaremchuk A. Grit: A predictor of medical student performance. Education for Health. 2018;31(2). PMID: 3053105

20. Maddi S, Mathews MD, Kelly DR, Villarreal B, White M. The role of hardiness and grit in predicting performance and retention of USMA cadets. Military Psychology. 2012;24:19-28.

21. Salovey P, Mayer J. Emotional Intelligence. Imagination, Cognition and Personality. 1990;9:185-211.

22. Partido BB, Stafford R. Association between emotional Intelligence and academic performance among dental hygiene students. J Dent Educ. 2018;82(9):974-979. PMID: 30173194

23. Rode J, Brown K. Emotional intelligence relates to NCLEX and standardized readiness test. Nurse Educator. 2019;44(3):154-158. PMID: 30102644

24. Chew B, Zain A, Hassan F. Emotional intelligence and academic performance in first and final year medical students: a cross -sectional study. BMC Medical Education. 2013;13(44). PMID: 23537129

25. Gupta R, Singh N, Kumar R. Longitudinal predictive validty of emotional intelligence on first year medical students perceived stress. BMC Medical Education. 2017;17(139). PMID: 28821250

26. Carvalho V, Guerrero E, Chambel M. Emotional intelligence and health students' well-being: A two-wave study with students of medicine, physiotherapy adn nursing. Nurse Education Today. 2018;63:35-41. PMID: 29407258

27. Duckworth A. Angela Duckworth Research. https://angeladuckworth.com/research/. Published 2020. Accessed 2/29/20.

28. Duckworth A, Quinn P. Development and validation of the Short Grit Scale. Journal of Personality and Assessment. 2009;91(2). PMID: 19205937

29. Consortium for Research on Emotinal Intelligence in Organizations. The Mayer-Salovy-Caruso Emotional Intelligence Test. http://www.eiconsortium.org/measures/msceit.html. Published 2019. Accessed 9/24/19, 2019.

30. Brackett M SP. Measuring emotional intelligence with the Mayer-Salovey-Caruso Emotional Intelligence Test (MSCEIT). Psicotherma. 2006;18:34-41.

31. IBM SPSS Statistics [computer program]. Version 24: IBM Corp; 2016.

32. Christopoulou M, Lakioti A, Pezirkianidis C, Karakasidou E, Stalikas A. The Role of Grit in Education: A Systematic Review. Psychology. 2018;09(15):2951-2971.

33. Burkhart RA, Tholey RM, Guinto D, Yeo CJ, KA C. Grit: A marker of residents at risk for attrition? Surgery. 2014;155:1014-1022. PMID: 24856121 
34. Halbur B, A K. Grit of first- and second-year physical therapy students: A pilot study. Physical Therapy Scholarly Projects. 2017;664.

35. Mayer J, Salovey S, D C. MSCEIT Resource Report. Toronto, Canada 2004.

36. Parker JDA, Summerfeldt LJ, Hogan MJ, Majeski SA. Emotional intelligence and academic success: examining the transition from high school to university. Personality and Individual Differences. 2004;36(1):163-172.

37. Adeyemo DA. Moderating Influence of Emotional Intelligence on the Link Between Academic Self-efficacy and Achievement of University Students. Psychology and Developing Societies. 2007;19(2):199-213.

38. Nasir M, Masrur R. An Exploration of Emotional Intelligence of the Students of IIUI in Relation to Gender, Age and Academic Achievement. Bulletin of Education and Research. 2010;32(1).

39. Codier E, Odell E. Measured emotional intelligence ability and grade point average in nursing students. Nurse Educ Today. 2014;34(4):608-612. PMID: 23835081

40. Mayer J, Caruso D, Salovey P. Emotional intelligence meets standards for traditional intelligence. Intelligence. 2000;27(4):267-298. 